\title{
Integración de una red de innovación educativa. La experiencia de la RIE 360
}

\author{
Arodi Carvallo, José Escamilla, Elsa Fueyo, \\ Elvira Godínez, Patricia González, Jessica Hernández, \\ Alan Hernández, Mireya López, Ana María del Pilar \\ Martínez, Mirsa Montiel, Melchor Sánchez, \\ Mariana Sánchez, Ruth Torres, León Velázquez
}

\section{Resumen}

El propósito de este artículo es documentar la experiencia vivida por un equipo interinstitucional de trabajo a quien se le encomendó desarrollar propuestas innovadoras de solución al problema de abandono estudiantil durante el primer año de vida universitaria. El grupo, compuesto por académicos con experiencias diversas en innovación educativa, provenientes de instituciones de educación superior púbicas y privadas, evolucionó hacia la integración de una red de innovación educativa. Además de las propuestas de solución a la problemática planteada, se lograron resultados paralelos de gran valor, principalmente aprendizajes vinculados con el proceso de innovación, el fortalecimiento de las capacidades personales e institucionales, el trabajo en equipo y el desarrollo de lazos de colaboración interinstitucional. La sistematización de esta experiencia pretende ordenar y documentar lo vivido, mirarlo críticamente a la luz de sus resultados y reflexionar sobre sus implicaciones, tanto en el ámbito de la problemática que atiende como en las lecciones aprendidas durante la experiencia.

Palabras clave: colaboración interinstitucional, red, innovación educativa, instituciones de educación superior, abandono escolar.

1 Los autores aparecen en orden alfabético. 


\title{
INTEGRATION A NETWORK OF EDUCATIONAL INNOVATION. THE EXPERIENCE OF RIE 360
}

\begin{abstract}
The purpose of this paper is to document the working process of an inter-institutional group of professionals which was entrusted to devise innovative solutions to the on-going problem of student dropout during the first year of university life. The group, comprised of academics from public and private higher education institutions with diverse backgrounds in teaching innovation, ultimately transitioned into a network for educational innovation. In addition to proposing solutions to the original problem, significant analogous data was obtained; discoveries regarding the innovation process, the strengthening of personal and institutional capabilities, team work and the development of inter-institutional collaboration links. The systematization of this experience pretends to organize and document this growth process, look critically at the results, and reflect on its implications, regarding its fundamental purpose and the findings that surfaced through the entire process.
\end{abstract}

Key words: inter-institutional collaboration, network, educational innovation, higher education institutes, school dropout.

\section{Introducción}

El papel de las universidades e instituciones de educación superior (IES) ha evolucionado a lo largo de la historia, desde sus orígenes en la universidad medieval la cual estuvo orientada a la preservación del conocimiento y a la formación de las élites, hasta las primeras décadas del siglo XXI en que estas instituciones se han visto confrontadas por los retos de la globalización, del desarrollo sostenible y del cambio tecnológico.

Las demandas a las que se ven expuestas las IES en la actualidad son múltiples, y provienen de diversos actores y contextos, tanto internos como externos. Uno de los retos más importantes radica en ampliar la cobertura y asegurar que los estudiantes puedan tener los soportes institucionales que garanticen trayectos académicos de calidad, pertinentes y efectivos, favorezcan su permanencia, propicien la trayectoria académica esperada y la graduación oportuna.

Con estos propósitos, a finales de 2016, se reunió un grupo de rectores de universidades públicas y privadas en el marco del Tercer Congreso de Innovación Educativa organizado por el Instituto Tecnológico y de Estudios Superiores de Monterrey (ITESM) en la Ciudad de México. Las autoridades fueron convocadas para asistir a un encuentro con Michael Crow, rector de la Universidad Estatal de Arizona, quien expuso diversas experiencias interinstitucionales de vinculación entre universidades públicas norteamericanas, que ha permitido 
2. La reunión, denominada "Diálogo de Rectores", se realizó el 14 de diciembre de 2016, en el marco del Tercer. Congreso de Innovación Educativa, organizado por el ITESM en la Ciudad de México. atender colaborativamente a los estudiantes de las instituciones participantes, optimizando los recursos financieros, tecnológicos y humanos con que cuenta cada universidad.

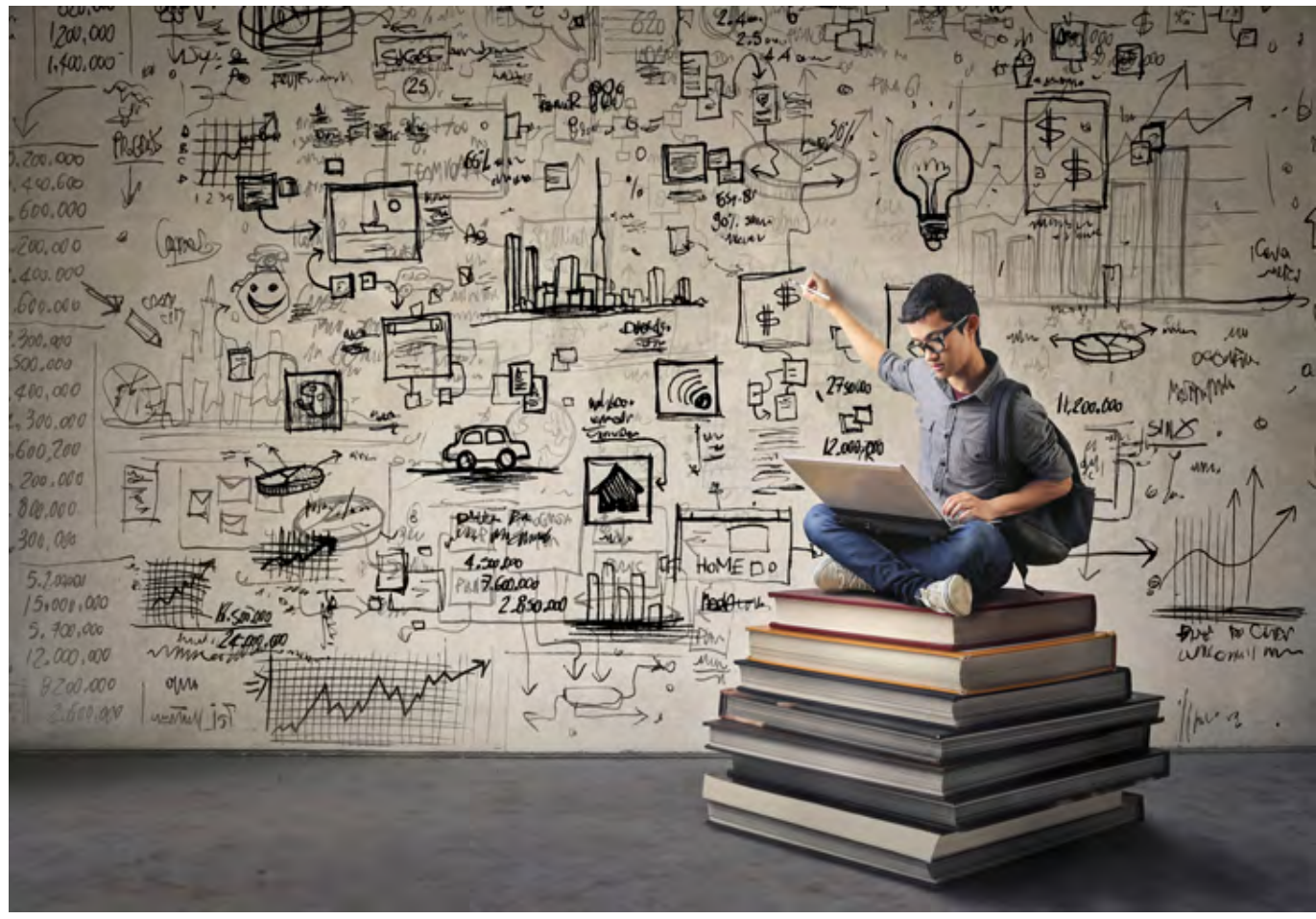

En este encuentro, el grupo de directivos asistentes definió el siguiente enunciado conjunto: "Coincidimos en la necesidad de innovar y colaborar para impactar de manera más amplia en la solución de los problemas del país". ${ }^{2}$ Así mismo, se alcanzaron consensos tales como generar sinergias a través de las fortalezas, experiencias y capacidades de cada una de las instituciones participantes; impulsar estrategias de innovación educativa que coadyuven a disminuir el rezago y el abandono educativos - particularmente durante el primer año de vida universitaria-, y, en sentido general, mejorar la eficiencia terminal en los estudios de licenciatura.

\section{La conformación del grupo y el trabajo realizado}

Para hacer viable el logro de estos acuerdos, cada uno de los rectores nombró representantes institucionales para integrar un equipo de trabajo -que inicialmente se denominó 'Líderes de Innovación Educativa'-, conformado por participantes de las siguientes IES (citadas en orden alfabético): Benemérita Universidad Autónoma de Puebla (BUAP), Instituto Politécnico Nacional (IPN), Instituto Tecnológico y de Estudios Superiores de Monterrey (ITESM), Universidad Anáhuac (UA), Universidad Autónoma del Estado de México (UAEMEX), Universidad 
Iberoamericana (IBERO) y Universidad Nacional Autónoma de México (UNAM). La coordinación general de este grupo fue asumida de manera conjunta por esta última y el ITESM, con la encomienda de impulsar un proceso de colaboración interuniversitaria tendiente a generar soluciones innovadoras, viables y efectivas para atender el problema planteado.

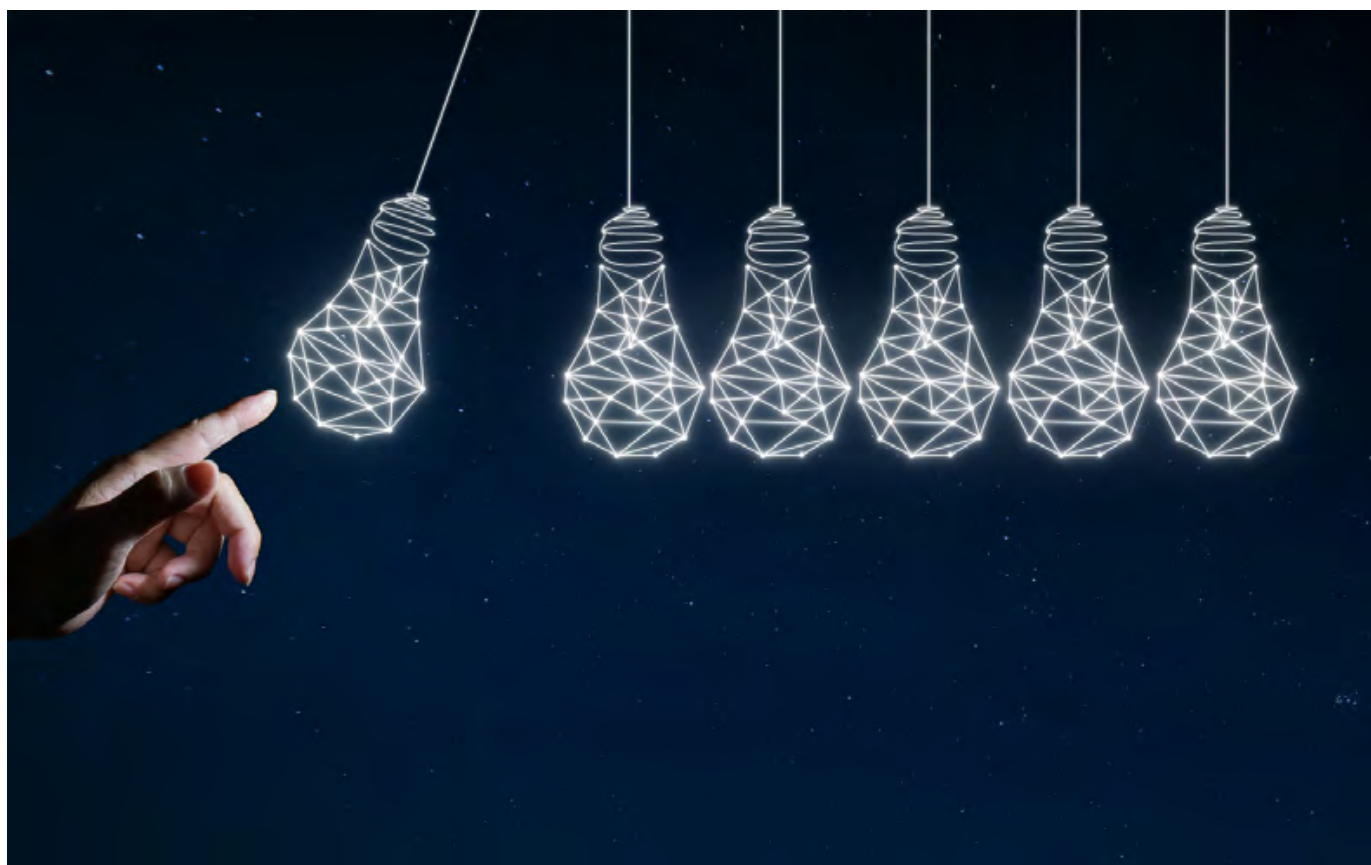

El trabajo del grupo inició en el mes de febrero de 2017 y ha continuado hasta el momento. Empezó con la designación de los representantes propuestos por las distintas instituciones participantes y la convocatoria para integrar un grupo de trabajo. Como resultado de ello, en el lapso de once meses se han realizado siete reuniones del grupo, en instalaciones de las diversas instituciones participantes, además de una reunión con los rectores y funcionarios en el mes de septiembre, en la que se les presentaron los avances y los pasos a seguir para la siguiente etapa.

En la primera fase de este proceso se realizaron actividades enfocadas a la exploración de experiencias exitosas de innovación educativa en México y otros países; se realizó un intercambio de información sobre los recursos con que cuenta cada una de las instituciones involucradas y se identificó un acervo de materiales en los que se ha investigado el problema; se discutieron las perspectivas y delimitación del mismo; e inició la búsqueda de propuestas de solución haciendo uso de diversas metodologías, entre otras la denominada Design Thinking (DT). Esta dinámica de trabajo puede verse reflejada, grosso modo, en la siguiente figura: 
Figura 1. Actividades del proceso
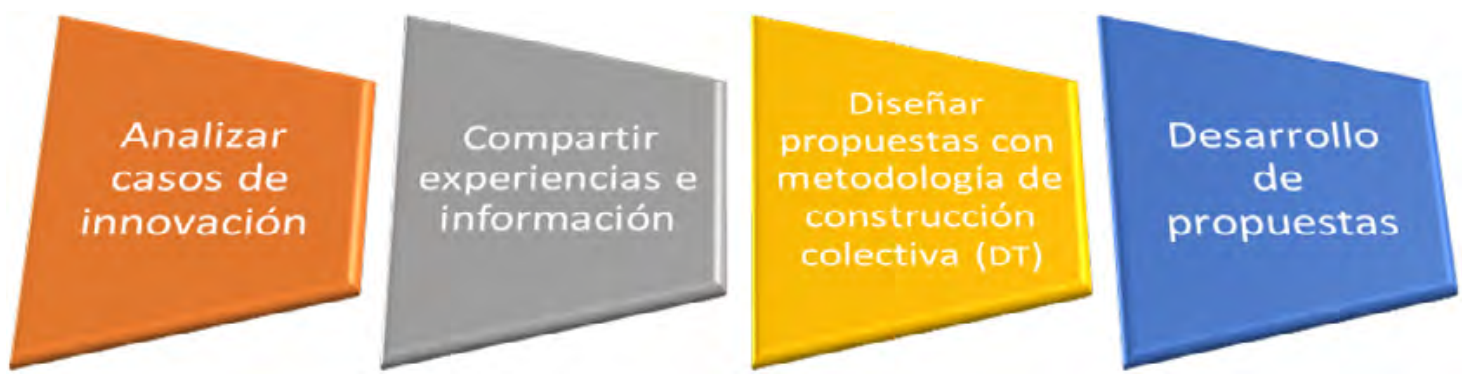

Enseguida, se explicarán sucintamente las diversas actividades realizadas en torno a estos ejes.

\section{Analizar casos de instituciones que han realizado experiencias innovadoras de desarrollo educativo}

Se presentaron y analizaron los casos de la University Innovation Alliance (UIA), Global Freshman Academy, de Arizona State University y Singularity University, los cuales representan formas innovadoras de organización para la colaboración institucional e interinstitucional, que trascienden los modelos tradicionales de operación de la educación superior. Estas experiencias se revisaron usando la metodología del cuadrante de análisis de casos, la cual permitió identificar y clasificar factores y elementos positivos y negativos de cada una de ellas, así como registrar preguntas e ideas sobre la colaboración a desarrollar, a partir de la exposición y el estudio de los casos presentados. La discusión en torno a éstos, permitió identificar las acciones particulares que constituirían un reto para la tarea encomendada al grupo.

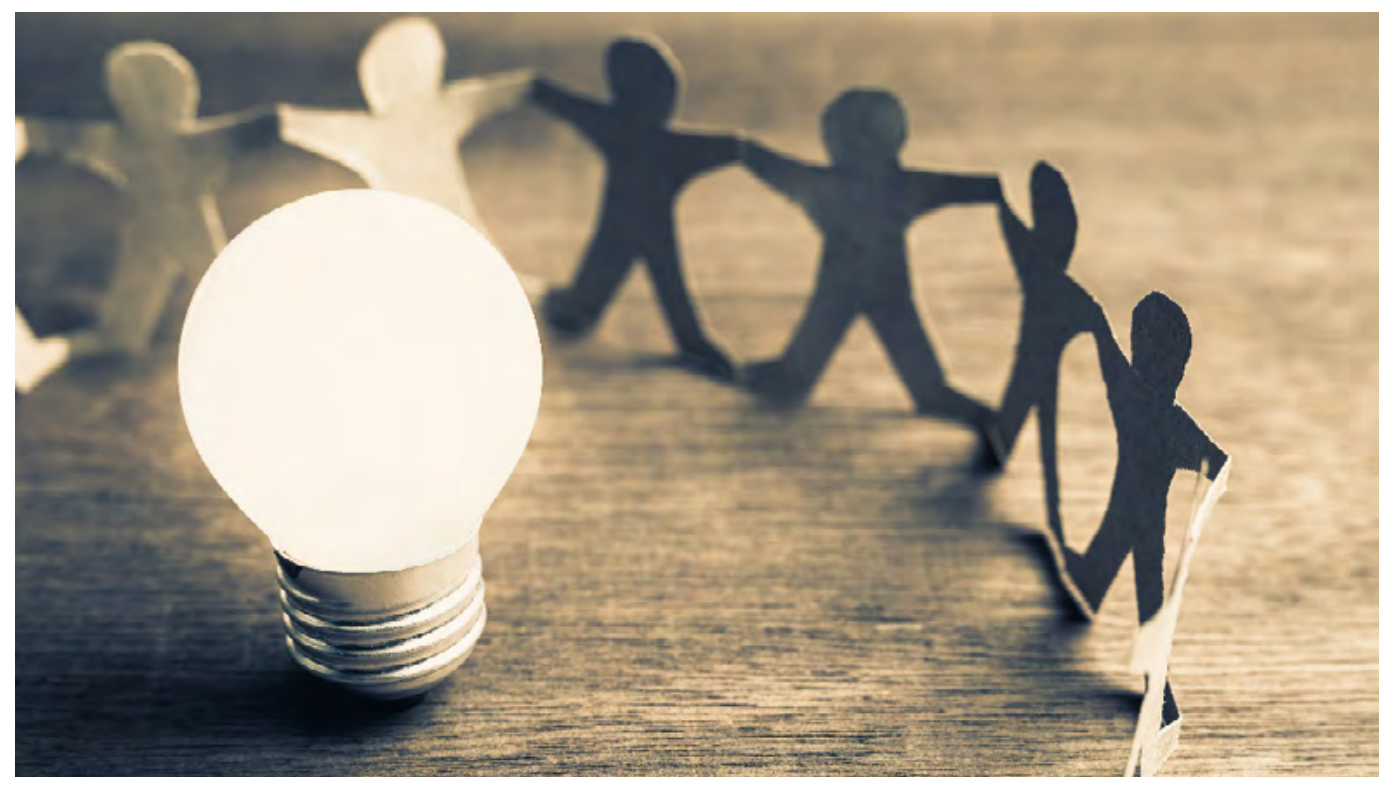




\section{Compartir experiencias innovadoras de cada una de las instituciones participantes}

Como parte del proceso de integración de los miembros de la red, se identificaron experiencias relevantes que dieron cuenta de procesos de innovación educativa dentro de cada una de las instituciones; las diversas experiencias institucionales que se presentaron fueron ubicadas en los siguientes ámbitos:

- Estrategias y programas para la formación docente: cursos, observatorios, plataformas de experimentación, proyectos para impulsar la innovación de la práctica docente.

- Estrategias y modalidades basadas en tecnologías para la educación y el aprendizaje: cursos, investigación, desarrollo de productos, evaluación de experiencias.

- Programas de apoyo para estudiantes: becas, programas para favorecer la inclusión, la equidad y la permanencia de los estudiantes en las IES, tutorías y otras acciones relacionadas con estrategias compensatorias.

- Programas académicos interinstitucionales, con diversas formas de organización y gestión académica.

- Experiencias de modificación radical o incremental en la organización y la normatividad institucionales.

- Programas y repositorios de materiales y recursos educativos.

- Proyectos de desarrollo de la infraestructura para la innovación educativa, en particular laboratorios.

Se compartieron y discutieron resultados de investigación en torno a la temática del abandono escolar la permanencia y la eficiencia terminal, que pudieran ser pertinentes para fundamentar el trabajo. En particular se exploraron resulta-

3. La Dra. Marisol Silva Laya es investigadora y directora del Instituto de Investigación para el Desarrollo de la Educación

(INIDE) de la Universidad Iberoamericana. Sobre el tema ha publicado diversos artículos y dos textos: Silva Laya, M. y A. Rodríguez (2012).

El primer año universitario entre jóvenes provenientes de sectores de pobreza: un asunto de equidad. México, ANUIES. 175 pp.; Silva Laya, M. (2015). La importancia del primer año universitario. De la teoría a la práctica. México, Universidad Iberoamericana. $132 \mathrm{pp}$. dos de la investigación realizada por la Dra. Marisol Silva Laya, ${ }^{3}$ sobre la problemática del primer año de vida universitaria y sus implicaciones en las estrategias de las instituciones de educación superior. Y como complemento de esta tarea, la doctora Silva accedió a participar en una videoconferencia con el grupo.

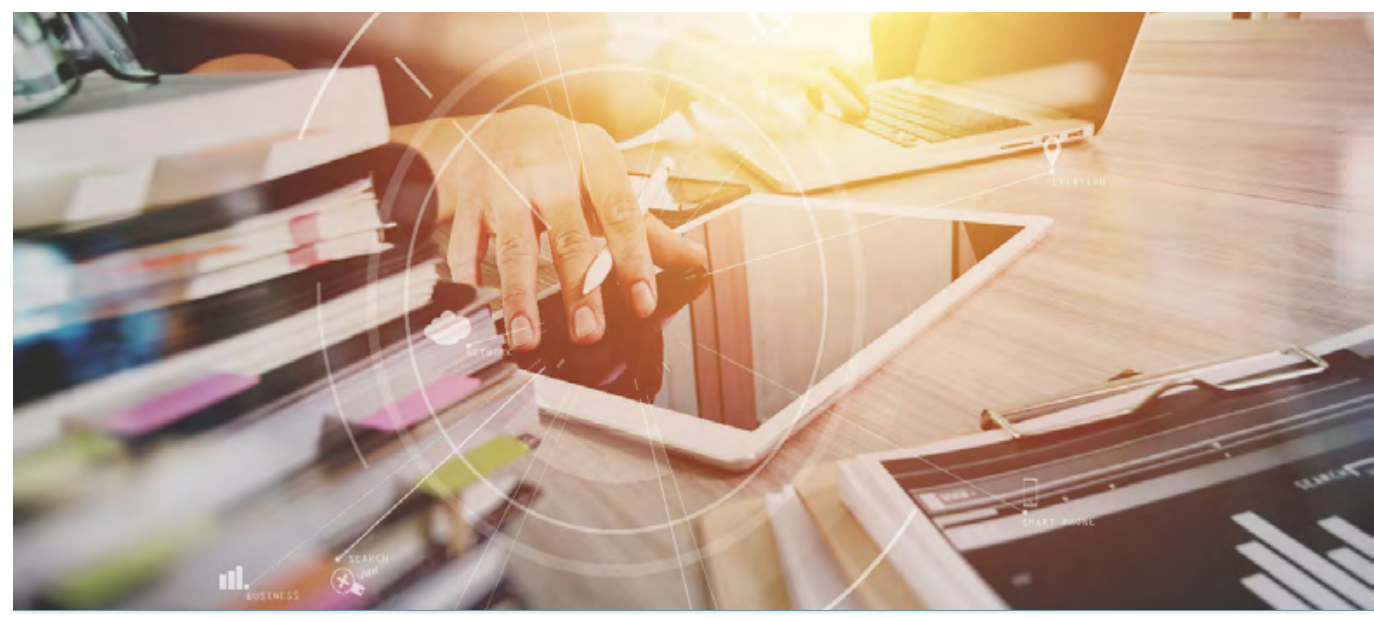




\section{Diseñar propuestas centradas en el usuario enfocadas a la solución de los problemas de abandono estudiantil}

Como punto de partida para detonar el proceso de diseño de propuestas, se planteó una pregunta inicial, generada por consenso entre los participantes:

¿Cómo diseñar experiencias de aprendizaje irresistibles e innovadoras para solventar deficiencias de los estudiantes y profesores, en competencias básicas (escribir, estudiar, autogestión) que incrementen la permanencia durante el primer año?

A partir de ella se desarrollaron diversas actividades siguiendo la metodología de DT.

\section{La metodología DT}

La metodología DT se centra en el usuario, es un trabajo colaborativo que impulsa procesos de pensamiento divergente y convergente en torno a un asunto o problema con el fin de generar disrupciones en los conceptos establecidos y en las soluciones convencionales existentes, que deriven en propuestas creativas e innovadoras. La metodología consta de las etapas que se muestran en la siguiente figura:

Figura 2. Etapas de la metodología Design Thinking

- Comprender profundamente la necesidad

Empatizar

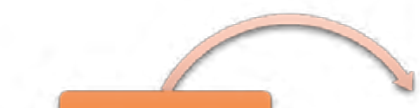

Definir

- Focalizar el ámbito del problema

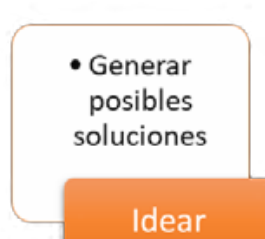

Idear
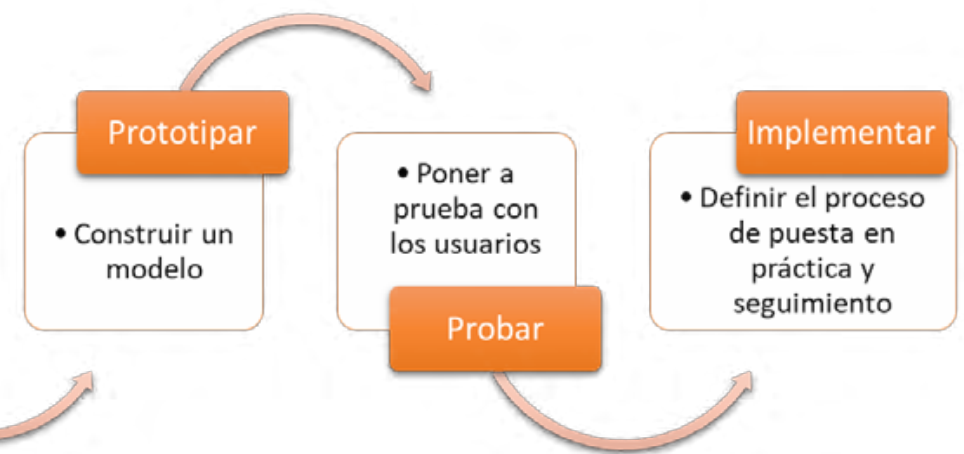

La metodología impulsa procesos de pensamiento creativo, que transitan desde la comprensión profunda de las necesidades de los usuarios o de las personas afectadas por una decisión; focalizan el ámbito del problema para definirlo con claridad y establecer sus límites y condiciones de ejecución; y se enfocan a generar posibles soluciones viables y explorar su pertinencia y efectividad. El proceso prosigue con la toma de decisiones consensuadas sobre la solución 
considerada más conveniente, para continuar con la etapa de desarrollo de un prototipo susceptible de ser confrontado con los usuarios potenciales para una valoración crítica.

Los integrantes de la red trabajaron con esta metodología, combinando, por una parte, el análisis de las diversas variables y de los factores que inciden en el problema del abandono estudiantil y sus manifestaciones en la eficiencia terminal; $y$, por otra, profundizando en las características, intereses y necesidades de los estudiantes a quienes se busca favorecer.

Con la intención de conocer a fondo la perspectiva de los usuarios, se entrevistó a estudiantes de primer año en la universidad, a quienes se presentó el prototipo propuesto para escuchar sus puntos de vista y sugerencias sobre éste; igualmente se les cuestionó acerca de sus vivencias al ingresar a la educación superior. La información obtenida permitió al grupo romper estereotipos sobre los jóvenes universitarios. La nueva visualización de la complejidad de la problemática llevó al planteamiento de un sistema de recursos y soluciones tendientes a satisfacer las necesidades de los diversos actores involucrados: estudiantes, profesores, tutores y directivos. Asimismo, se definió un sistema cuyo producto central será una aplicación web para uso de los estudiantes, que les permitirá contar con diversas herramientas, contenidos y recursos que las instituciones pondrán a su alcance para apoyar su desarrollo académico y personal.

La aplicación se complementa con productos adicionales que contextualizan y fundamentan la participación de otros actores: una página web que conecta con la aplicación, servicios de tutoría especializada y de pares, materiales educativos y productos de investigación, entre otros.

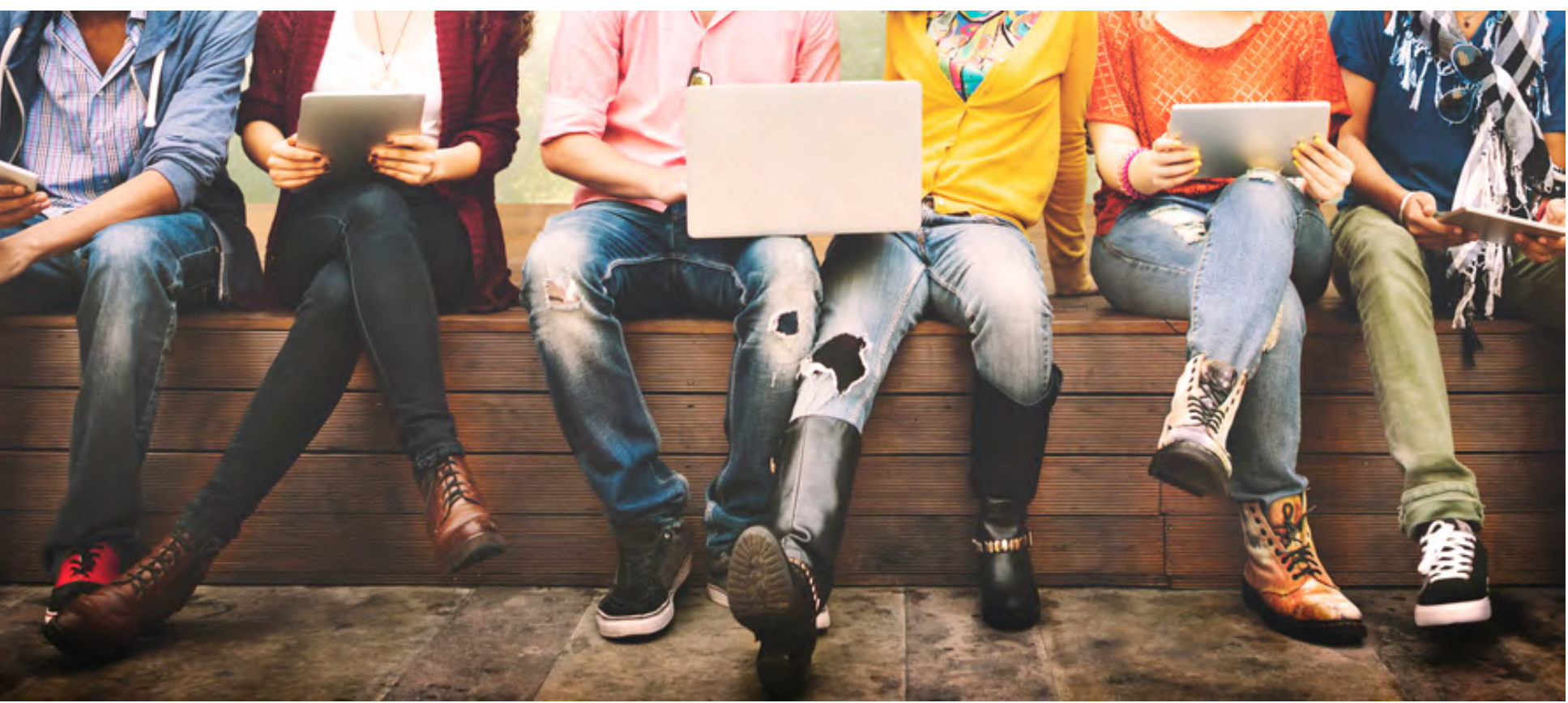




\section{De grupo de trabajo a red de colaboración}

La interacción entre los integrantes y la dinámica de trabajo que se desarrolló, devino en la creación de una red de colaboración interinstitucional orientada a la innovación educativa, denominada Red de Innovación Educativa 360 (RIE 360).

Las actividades realizadas durante las sesiones generaron entre los participantes un clima de confianza que permitió vencer resistencias y prejuicios enraizados sobre las características y problemáticas que viven IES públicas y privadas, encontrando que son más los elementos comunes que los que nos separan. Se detonaron así procesos de pensamiento creativo, colaboración, reconocimiento mutuo y compromiso con el proyecto.

En este ambiente se logró que los procesos de toma de decisiones se realizaran horizontalmente y por consenso, que se integraran las fortalezas personales e institucionales al servicio del proyecto, al complementar las cualidades y cubrir las carencias, focalizando el esfuerzo hacia el logro de los objetivos. Estas características del proceso grupal generaron condiciones para la integración de la red.

Según Luna y Velasco (2009), las redes son sistemas o estructuras complejas integradas por actores diversos, que cruzan barreras organizativas, sectoriales, institucionales, culturales o territoriales para colaborar, sin perder su autonomía y capacidad de autorregulación. Son estructuras dinámicas, multicéntricas, que permiten establecer vínculos.

Existen dos elementos fundamentales para el análisis de las redes: por una parte, su propósito, es decir los motivos y circunstancias para su creación, sus fines y objetivos; por otra, su estructura: los nodos, los vínculos y el contenido.

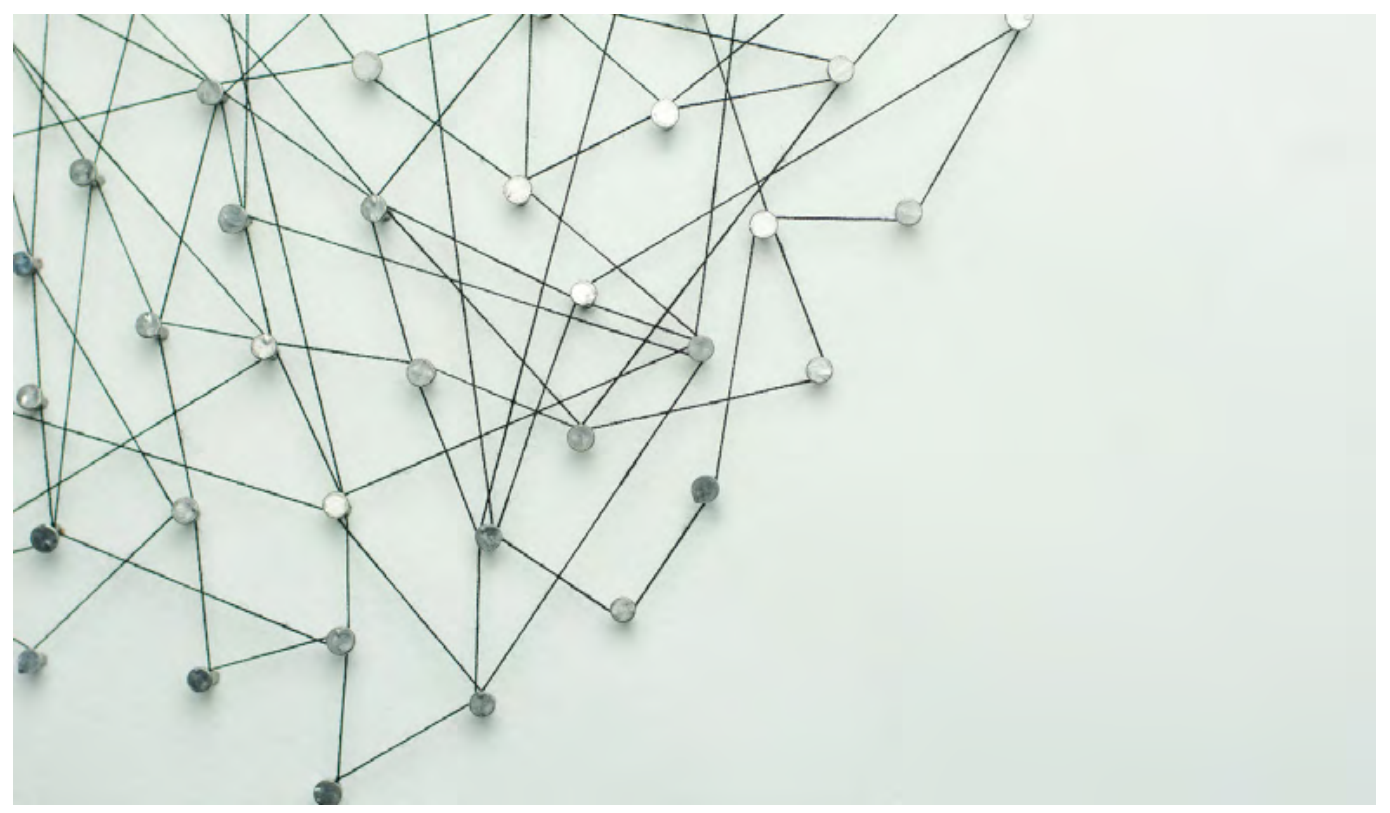


En el caso de la RIE 360, el propósito de la red está definido por la relevancia de la problemática común a todas las instituciones que la integran: los índices de rezago o abandono de los estudiantes de educación superior, particularmente en el primer año de estudios, y la necesidad de atender a los estudiantes en riesgo de abandono, que es el propósito prioritario que generó la cohesión entre los integrantes.

En cuanto a la estructura, los nodos son los actores, personales o institucionales, que se articulan y organizan para colaborar, interactuar y potenciar sus recursos y sus resultados. Los vínculos se definen como la naturaleza, dirección e intensidad de las relaciones entre los actores; finalmente, el contenido es el elemento que cohesiona a la red: la información, recursos, objetivos o productos que fluyen o se intercambian en distintas direcciones. Estas características de una red pueden apreciarse en la siguiente figura:

Figura 3. Elementos de la red

Fuente:

Sánchez Saldaña, 2012.

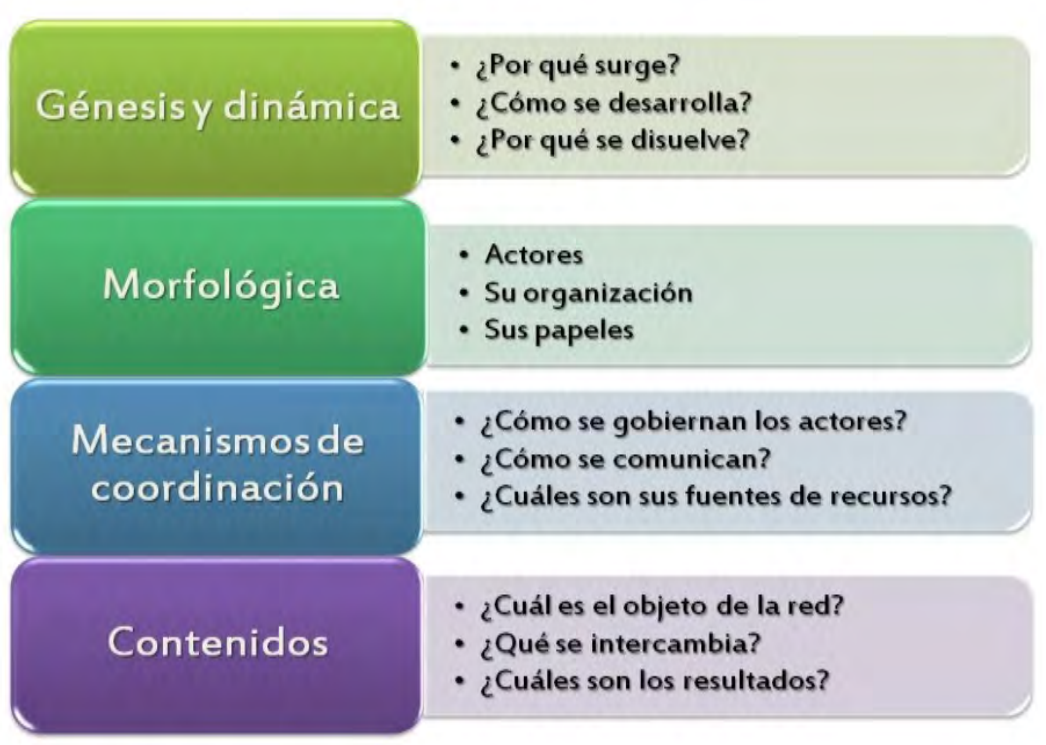

En el proceso de integración de la RIE 360 se han puesto en juego estos cuatro elementos fundamentales para el desarrollo de su estructura:

1. Génesis y dinámica. La decisión de colaboración se estableció de manera voluntaria y horizontal por parte de los rectores convocantes, y ese mismo espíritu se trasladó a la integración del grupo de los representantes institucionales, entre quienes se ha generado un clima de confianza, respeto, tolerancia y entusiasmo que ha propiciado la cohesión. 


\section{A diferencia de este} caso, hay redes que requieren procesos de traducción de propósitos, marcos de referencia o lenguajes para lograr el entendimiento y para solventar los conflictos, por lo que, en lugar de basarse en la deliberación, las decisiones se toman después de procesos de negociación. La necesidad de negociación es una función inversa a la confianza entre los miembros de la red, de la misma manera en que la necesidad de traducción entre los integrantes es inversa a la deliberación de las decisiones.
2. Morfología. Los integrantes de la red también han generado un sistema de comunicación entre los nodos-actores, con mecanismos, códigos y herramientas que inicialmente no eran parte del lenguaje de cada uno de los participantes. Este proceso es un factor que le dio viabilidad al trabajo de la red al favorecer las relaciones y el entendimiento entre los integrantes.

3. Mecanismos de coordinación. A lo largo del proceso se ha construido una estrategia de toma de decisiones, que considera la manera en que se procesan los posibles conflictos y se coordinan las acciones entre actores heterogéneos, con intereses, necesidades y preferencias comunes y a la vez distintas, para llegar a acuerdos aceptables para todos. La estrategia de toma de decisiones basada en la confianza mutua, en la aceptación de las capacidades estratégicas y técnicas de los miembros o en los acuerdos normativos previos, ha sido la deliberación (Casas, 2003). ${ }^{4}$

4. Contenidos. El trabajo de la red se ha alimentado con las aportaciones de todos los miembros. Los contenidos que se intercambian en la red son de naturaleza diversa: información, recursos académicos y tecnológicos, habilidades personales para la integración de equipos de trabajo, resultados de investigación, expertos, competencias metodológicas e infraestructura, entre otros. Lo que resulta relevante es que, a lo largo del proceso, todos los integrantes han podido aportar algo para el desarrollo de los productos y el logro de los objetivos.

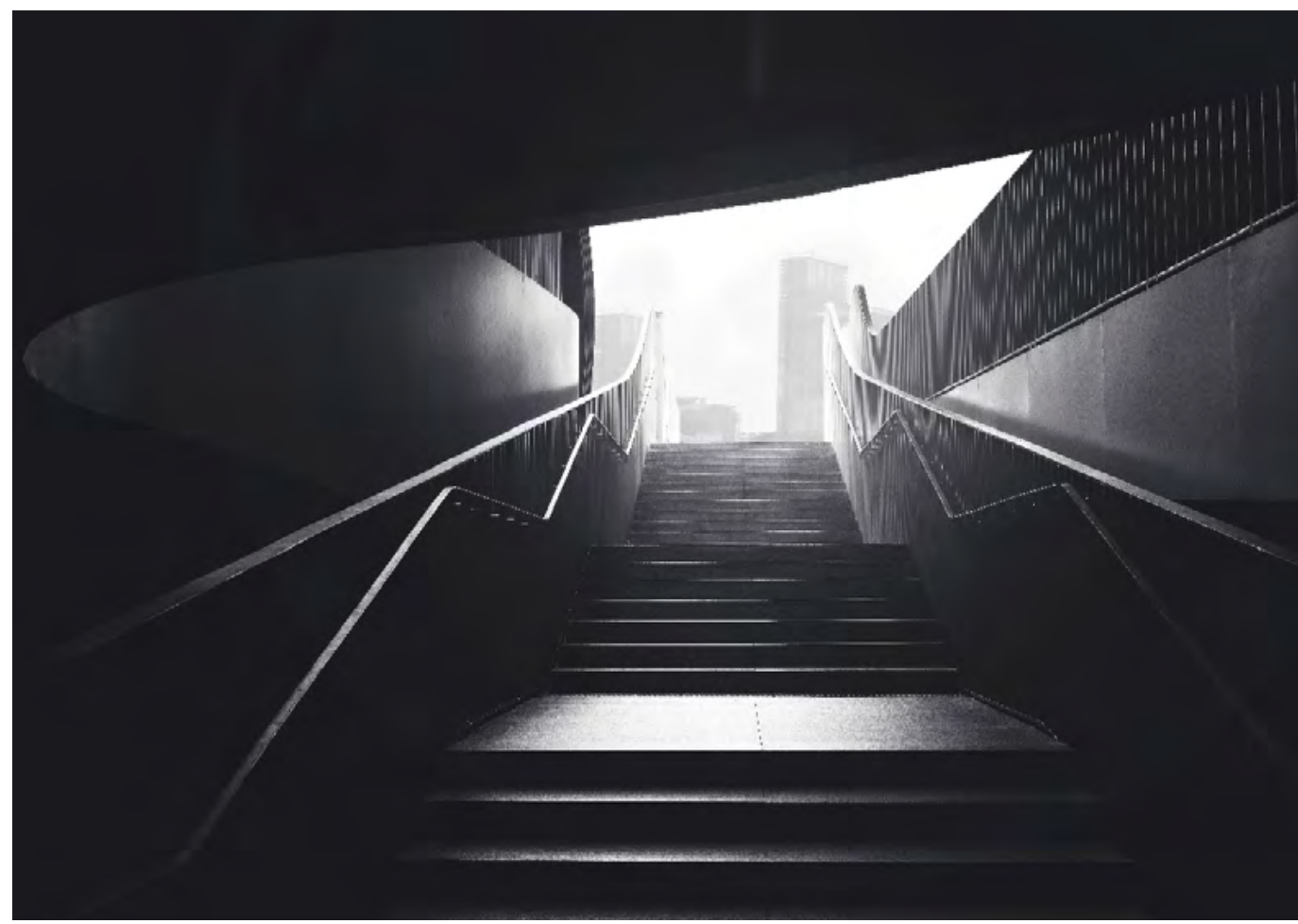


Estudiosos del fenómeno de las redes han identificado que aquéllas que logran sus objetivos tienen algunas características comunes que se convierten en el sustrato propicio para un trabajo conjunto (Casas, 2003; Chan, 2004; Luna y Velasco 2005 y 2009). En primer lugar, las redes exitosas tienen valores compartidos y objetivos comunes, integrados bajo un propósito unificador. Conservan su identidad y características propias, lo que constituye su atractivo y fortaleza principal y les permite, a la vez, conservar su independencia. Los miembros de estas redes se comunican de manera permanente, a través de canales multidireccionales, con lo cual la información fluye, no solo de manera vertical como quizá suceda en las organizaciones participantes, sino también horizontalmente aun cuando la complejidad de la estructura incluya múltiples niveles. Esto es posible porque todos los miembros reconocen que cada uno tiene algo valioso que aportar, lo que representa en la operación un liderazgo múltiple. La figura 4 sintetiza las características de las redes funcionales, que se encuentran presentes en la RIE 360:

Figura 4. Características de redes funcionales

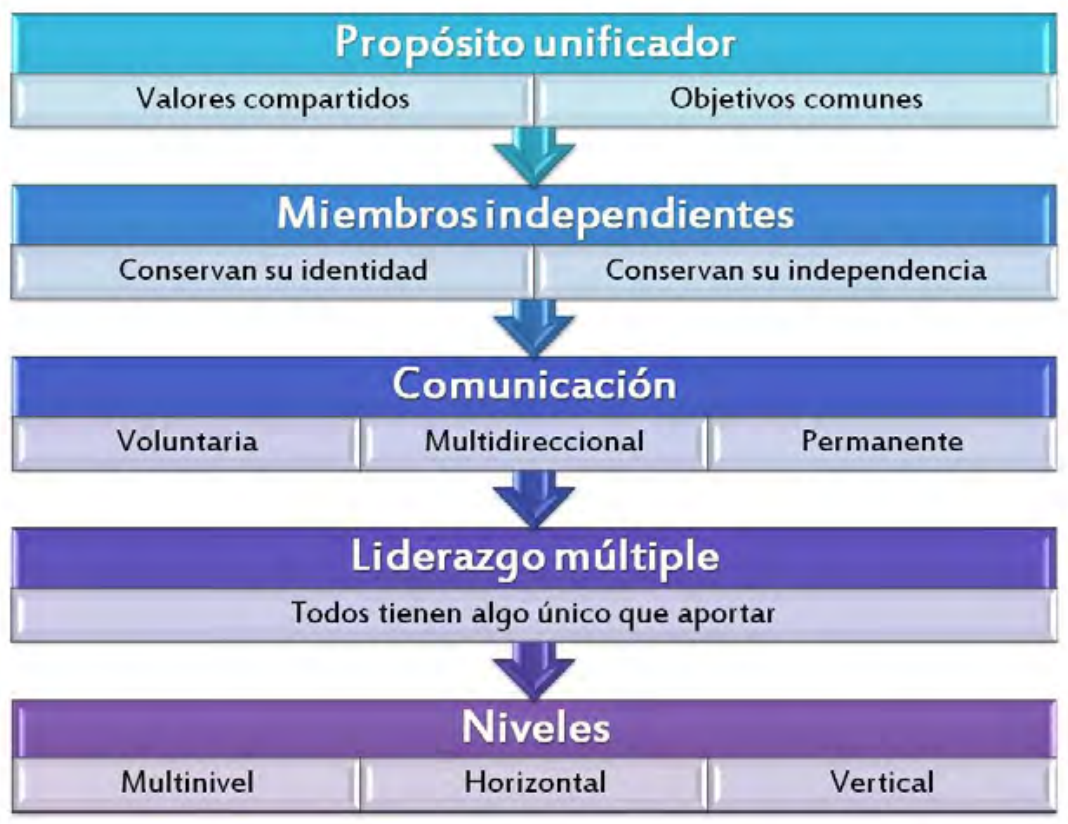

\section{A modo de conclusión. Perspectivas a futuro de la RIE $\mathbf{3 6 0}$}

Si bien en este momento existe un consenso favorable en torno a la integración de la RIE 360 como un instrumento poderoso para la creación de sinergias enfocadas al logro de objetivos, es importante identificar también los desafíos a los 
que se enfrenta por su condición de organización vulnerable, entre los cuales destacan:

1. La posibilidad de cambios en la relevancia de los objetivos iniciales para los distintos integrantes de la red, como resultado de cambios en el contexto o en las condiciones para la participación de los actores.

2. Las distintas interpretaciones sobre los propósitos iniciales de la red, que pueden no ser tan claros para nuevos integrantes que se incorporan para sustituir en un momento dado a los iniciadores, situación común en la dinámica de las instituciones de educación superior.

3. Aunque es un tema que se ha comentado en el grupo de trabajo, existe el peligro de que la orientación individualista en la cultura de algunas instituciones inhiba las acciones colaborativas.

4. El agotamiento de los recursos que alimentaron el surgimiento de la red, es decir, la falta de sostenibilidad de la organización.

Es claro que aún hay mucho camino por recorrer, ya que los objetivos de la RIE 360 están aún lejos de lograrse, en gran medida por ser objetivos complejos y ambiciosos. Pero los avances logrados en esta primera etapa son alentadores y muestran que es posible el trabajo conjunto entre instituciones diversas, públicas y particulares, con distintas formas de gobierno y financiamiento, así como con historias, identidades y trayectorias que inicialmente parecían incompatibles.

\section{Referencias}

* Casas, R. (2003). Enfoque para el análisis de redes y flujos de conocimiento. En M. Luna, Itinerarios del conocimiento: formas dinámicas y contenido. Un enfoque de redes (pp. 19-50). México: Anthropos Editorial-Instituto de Investigaciones Sociales, UNAM.

* Chan, W. W. (2004). International Cooperation in Higher Education: Theory and Practice. Journal of Studies in International Education, 8 (1), pp. 32-55. DOI: https:// doi.org/10.1177/1028315303254429.

* Luna, M., y Velasco, J. L. (2005). Confianza y desempeño en las redes sociales. Revista Mexicana de Sociología, 67 (1) enero-marzo, pp. 127-162. Recuperado de: http://www.revistas.unam.mx/index.php/rms/article/view/6014.

* Luna, M., y Velasco, J. L. (2009). Las redes de acción pública como sistemas asociativos complejos: problemas y mecanismos de integración. REDES: Revista hispana para el análisis de redes sociales (pp. 76-99). Recuperado de: http://revista-redes. rediris.es/pdf-vol17/vol17 4.pdf.

* Sánchez-Saldaña, M. (2012). Políticas de Posgrado. Procesos coaliciones y efectos de su aplicación en México (tesis de doctorado en Educación). CDMX, México: Universidad Iberoamericana. 
* Silva Laya, M. (2015). La importancia del primer año universitario. De la teoría a la práctica. México, Universidad Iberoamericana. 132 pp.

- Silva Laya, M. y A. Rodríguez (2012). El primer año universitario entre jóvenes provenientes de sectores de pobreza: un asunto de equidad. México, ANUIES. 175 pp.

\section{Cómo citar este artículo}

* Carvallo, A., Escamilla, J., Fueyo, E., Godínez, E., González, P., Hernández, J., Hernández, A., López, M., Martínez, A.M P., Montiel, M., Sánchez, M., Sánchez, M., Torres, R., Velázquez, L. (2018). Integración de una red de innovación educativa. La experiencia de la RIE 360. Revista Digital Universitaria (RDU). Vol. 19, núm. 1 enero-febrero. DOI: http://doi.org/10.22201/codeic.16076079e.2018. v19n1.a5. 